IN-2O

NASA Contractor Report 195419

0705.5

\title{
Influence of Power System Technology on Electric Propulsion Missions
}

Steven R. Oleson

NYMA, Inc.

Engineering Services Division

Brook Park, Ohio

January 1995

Prepared for

Lewis Research Center

Under Contract NAS3-27186

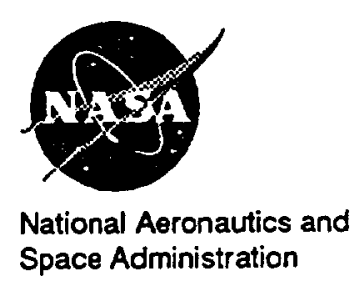





\title{
INFLUENCE OF POWER SYSTEM TECHNOLOGY ON ELECTRIC PROPULSION MISSIONS
}

\author{
Steven R. Oleson \\ NYMA, Inc. \\ Engineering Services Division \\ Brook Park, Ohio 44142
}

\begin{abstract}
Electric propulsion (EP) thruster technology, with efficient lightweight power systems can provide substantial reductions in propulsion system wet mass due to the high specific impulse (Isp) of the thrusters. Historically, the space power systems are too massive for many potential orbital missions. The objective of this paper is to show the impact of current power system technology on EP mission performance and determine what technology advancements are needed to make EP beneficial for earth orbital applications. The approach of the paper is to model the electric propulsion system and orbital mission using a partial parametric method. Various missions are analyzed from orbit maintenance to orbit transfer. Results portray the relationship between mission performance and power technology level. Conclusions show which mission applications currently have acceptable power technology, and which mission applications require power technology improvements.
\end{abstract}

\section{Introduction}

Electric propulsion (EP) thruster technology has been available for the last three decades. EP, with efficient lightweight power systems can provide substantial reductions in propulsion system wet mass due to the high specific impulse (Isp) of the thrusters. However, the application of EP to a variety of missions is just beginning to occur. One of the main reasons is that the power system required by EP to provide substantial mission benefits (lower masses, acceptable trip times, and lower costs) has not been available; historically the space power systems are too massive for many potential orbital missions.

The objective of this paper is to show the impact of current power system technology on EP mission performance and determine what technology advancements are needed to make EP beneficial for earth orbital applications. This paper focuses on earth orbital applications where the majority of space missions occur. The approach of the paper is to model the electric propulsion system and orbital mission using a partial parametric method based on the Edelbaum equation. Several representative EP thruster systems are chosen along with some representative power systems. These EP and power technologies are modelled parametrically to make the results applicable to a range of spacecraft masses and power levels. Various missions are analyzed from orbit maintenance to orbit transfer. Combining EP systems and power systems with different missions shows the relationship between mission performance, power technology level, and spacecraft power level / initial mass ratio. Conclusions show which mission applications currently have sufficient power technology, and which mission applications require improvements in power technology.

\section{Economy of Scale}

EP spacecraft are modelled parametrically by scaling propulsion and power subsystem masses to power level to define a specific mass $(\alpha)$. While this method allows for using the results for any power/mass/technology combination its results may be misleading due to the non-linearity of the propulsion and power system scaling. This is caused by the economy of scale that larger power and propulsion systems have over smaller power systems of the same type.

\section{EP Vehicle Analysis}

An EP vehicle is modeled by four main elements each of which contributes to the total mass (Mo) of the EP vehicle: the propellant mass $(\mathrm{Mp})$, the propellant tankage $\left(\mathrm{Kt}^{*} \mathrm{Mp}\right)$, the propulsion and power system $\mathrm{Mw}$, and the payload $\mathrm{Mn}$ (referred to as net mass). A more complete derivation is provided by Oleson 1 . These subsystem masses combine to make the total initial EP vehicle mass:

$$
\mathbf{M o}=\mathbf{M n}+\mathbf{M w}+\mathbf{M p}+\mathrm{K}_{\mathrm{t}} \mathbf{M p} \text {. }
$$

The propellant mass is calculated using the rocket equation.

$$
\mathrm{Mp} / \mathrm{Mo}=1-\mathrm{e}^{-\Delta \mathrm{v} / \mathrm{c}} \text {. }
$$

Where $\Delta \mathrm{V}$ is the mission's equivalent velocity change and $\mathrm{c}$ is the electric thrusters exhaust velocity. From Oleson ${ }^{1}$ the net mass / initial mass ratio or net mass fraction is:

$$
M n / M o=e^{-\Delta v / c}-\left[K_{t}+\left(\alpha c^{2}\right) /(2 \eta t)\right]\left(1-e^{-\Delta v / c}\right)
$$

where $\eta$ is overall propulsion system efficiency and $t$ is thrusting time. The required propulsion power level / initial vehicle mass ratio or power density is simply:

$$
\mathrm{Po} / \mathrm{Mo}=\left(\mathrm{c}^{2}\right) /(2 \eta \mathrm{t})\left(1-\mathrm{e}^{-\Delta \mathrm{v} / \mathrm{c}}\right)
$$

and is independent of power system specific mass.

\section{Analytically Optimal Net Mass Fraction}

It has been shown in Stuhlinger ${ }^{2}$, Gilland ${ }^{3}$, and Oleson ${ }^{1}$ that there exists an optimal Isp which provides an optimal net mass fraction for a desired trip time or provides an optimal trip time for a desired net mass fraction. Most thruster technologies have a fairly broad band of operating Isps (hundreds to thousands of seconds). To simplify this analysis, however, the nominal specified thruster Isp is used which in most cases is nonoptimal. Such nonoptimal Isps are still representative of optimal Isp performance.

\section{Propulsion Systems}

Three propulsion systems are chosen for this analysis. The propulsion system is made up of a thruster, a gimbal, a power processing unit (PPU), a control unit, and associated cabling and structure. Table 1 provides the type, Isp, overall efficiency (PPU and thruster), input power level, and reference as well as the specific masses. While all three systems have various power 
settings only the one setting (the highest Isp and efficiency) is considered to simplify the analysis. An explanation of how the thrusters operate may be found in Jahn6.

\section{Power Systems}

Several representative power systems are chosen for this analysis to represent the current state of technology. Included in the EP power system is generation source (e.g. arrays, reactors), power management and distribution (PMAD) (e.g. cabling, regulators and controllers). Not included in an EP power system is energy storage (batteries) since for most missions (except some orbit maintenance) the power for EP will almost always come from a generated source. While batteries are required by the spacecraft, their mass is not assessed to the EP system.

Many technologies are currently available for the power source and the PMAD. Power sources may be photovoltaic, static (radioisotope), and dynamic (nuclear reactor and solar thermal.) Power distribution is directly impacted by the bus voltage and the size of the spacecraft. Only the power distribution equipment used to send power to the PPUs is charged to the EP system. Power management deals with controlling the power source and regulating the bus voltage. Two methods can be used to control the spacecraft power source: peak-power tracker (PPT) and direct-energy-transfer (DTE). These methods are described by McDermott 7 . These two control methods may be combined with different levels of bus regulation depending on design requirements. Many combinations of PMAD and power source components may be used.

Table 2 provides the type, performance aspects, and reference including the specific masses of some representative power sources and PMAD subsystems. A complete power subsystem to support an EP system could have a specific mass anywhere from over $100 \mathrm{~kg} / \mathrm{kW}$ for a $1 \mathrm{~kW}$ solar thermal system to perhaps as low as $20 \mathrm{~kg} / \mathrm{kW}$ for a $25 \mathrm{~kW}$ solar photovoltaic system. While the radioisotope and nuclear reactor systems are substantially more massive than the photovoltaic systems they provide constant power when in earth's shadow where the photovoltaic systems power is nonexistent. For the examples in Table 2 the power source is usually the most massive part of the power system. However, the PMAD components are by no means trivial in mass and have a substantial impact on the total power system mass. When the EP system is not operating the EP power is available to the spacecraft and payload, thus enabling 'sharing' of the power.

It is evident from Tables 1 and 2 that the power system specific mass is of the same or greater magnitude as the propulsion system. This can be lessened somewhat by realizing that in some cases multiple thrusters operate simultaneously. This results in a higher propulsion system specific mass when compared to the power system specific masses (e.g. two $2.5 \mathrm{~kW}$ thrusters used with a $5 \mathrm{~kW}$ system.) Only photovoltaic and nuclear reactor power sources are considered due to their superior specific masses and applicability to electric propulsion.

\section{Mission Analysis}

To relate the mission performance requirements to vehicle parameters an equivalent velocity increment $(\Delta V)$ is used. This $\Delta V$ is related to the vehicle performance through the rocket equation [see equation (2)].

For orbit transfers an EP vehicle thrusts throughout most of its mission, thus an impulsive $\Delta \mathrm{V}$, (an assumption that all thrusting burns change the vehicle's velocity instantaneously), is not appropriate. However, past work done by Edelbaum ${ }^{10}$ gives an analytical expression (and accompanying assumptions) which approximates the $\Delta \mathrm{V}$ required by a low thrust vehicle performing an orbital transfer and a plane change between circular earth orbits. This expression is,

$$
\Delta \mathrm{V}=\left[\mathrm{V}_{0}^{2}+\mathrm{V}^{2}-2 \mathrm{~V}_{0} \cos (\pi / 2 * \Delta \theta)\right]^{1 / 2}
$$

where Vo and $\mathrm{V}$ are the circular velocities of the original and desired orbits, respectively, and $\Delta \theta$ is the desired plane change.

Expression (5) cannot be used for elliptical orbit transfers so the utilization of a numerical optimizer such as SECKSPOT is required to determine a representative $\Delta V$. These $\Delta V$ s only vary with initial orbital elements, shading, and oblateness effects; no impact on mission $\Delta V$ has been shown with the variation of the stage parameters (Isp, mass, power, efficiency.)

\section{Sample Missions}

Several sample missions are presented to show a range of low thrust equivalent $\Delta V$ 's. Table 3 gives the mission description, initial and final orbital elements, the corresponding $\Delta V$, and how it is determined.

\section{RESULTS}

Propulsion systems, power systems, and missions are combined to show each power/propulsion system's range of performance. Each propulsion system's highest Isp, highest efficiency, and lowest specific mass is chosen from Table 1 . The two specific mass extremes of photovoltaic ( 38.5 and $10 \mathrm{~kg} / \mathrm{kW}$ ) and nuclear reactor (67 and $45 \mathrm{~kg} / \mathrm{kW}$ ) power technologies are selected from Table 2 along with a PMAD specific mass of $10 \mathrm{~kg} / \mathrm{kW}$. For each mission in Table 3, a parametric chart is then created showing the range of each power/propulsion combination's performance in terms of net mass fraction versus thrusting time. This net mass fraction varies greatly with power level which in turn affects the required thrust time. The total transfer time is actually greater due to shading (for photovoltaic and solar thermal systems) and degradation (for photovoltaic systems). These higher order effects can increase the actual transfer time by factors of 1.1 to 2 of the thrust time. These factors will be used to translate the parametric data into useful conclusions.

For the orbit transfer cases this transfer time is an important parameter since the cost of satellite operations (depending on level of satellite autonomy) and cost of delaying actual satellite service must be acknowledged when considering improving the net mass fraction. For orbit maintenance the thrusting times are not as important as continuing payload operations during thruster operation. This can often be achieved by adding power system or utilizing the spacecraft's battery power as suggested by 
Free11. By this dual use of the existing battery the net mass fraction can be increased.

\section{LEO to GEO Mission}

A major portion of commercial and military satellites use Geostationary Orbit (GEO). Consequently, increasing the useable payload for a given launch vehicle or even reducing launch vehicle classes is attractive. By taking the three thruster systems from Table 1 and combining them with the photovoltaic and nuclear reactor power system specific mass limits Figures 1 and 2 are created. For current photovoltaic technology the graph shows at what thrusting times each thruster technology provides the highest net mass fraction. The figure also shows the approximate range of net mass fractions for chemical systems.

Both figures show that $\mathrm{N} 2 \mathrm{H} 4$ Arcjets only give comparable performance to existing chemical systems. The thrusting time for the nuclear reactor technology is roughly twice that of the photovoltaic. Shading only increases the photovoltaic trip time over the thrusting time by approximately a factor 1.1 . Considering shading and degradation of GaAs unshielded planar or APSA arrays the factor increases to about 1.7 for thrusting times under a year. While planar and APSA arrays can be shielded to reduce power degradation the addition in specific mass is usually prohibitive. Concentrator arrays reportedly have inherent shielding and degrade minimally but may require greater pointing accuracy11. Only when unshielded Si planar or APSA arrays are used does the factor worsen to 2 or more. Thus photovoltaic power systems using GaAs or better technologies outperform nuclear reactor technology.

The Xenon Hall thrusters initially outperform the Xenon Derated $30 \mathrm{~cm}(\mathrm{D}-30)$ thrusters up to about 150-230 days of thrusting depending upon the power system specific mass. At this crossover point both systems roughly double the net mass fraction. However, the required power density is about half for the Hall thruster system compared to the D-30 system as shown in Figure 3. The Hall system would need around 4 to $5 \mathrm{kw}$ per metric ton of spacecraft initial mass. Unfortunately, the Hall thruster's expected life ends around 150 days which would require extra thrusters (but not necessarily PPU's). This extra mass has not be added in Figure 1. To increase the net mass fraction even more would require the D-30 system combined with a lower power density. This changes the overall trip time accounting for shading to about 200-330 days depending upon power specific mass. Correspondingly, the required power density would range from about 9 to $7 \mathrm{kw}$ per metric ton of spacecraft initial mass.

The monetary cost of such trip times and propulsion/power systems is not calculated here but would have to be considered to truly prove the benefit of EP for LEO to GEO transfers. In addition the increase in net mass fraction will be decreased somewhat when considering the shielding required to protect the payload spacecraft (especially its electronics) during the long exposure time experienced when traversing the most damaging regions of the radiation belts (about 1000 to $10000 \mathrm{~km}$ altitude.)

For LEO to GEO missions in general, the delivered net mass fraction over chemical systems can be more than doubled by utilizing: trip times six months to a year, existing Hall and D30 thruster technology, and improving in the radiation resistance of current photovoltaic power sources without increasing specific mass. The new concentrator array systems currently seem to be the best choice for minimizing the radiation degradation while keeping specific masses at current levels. Pointing requirements for the concentrator arrays may also have to be relaxed to reduce the impact on attitude control. 11 To increase the net mass fraction even more will require longer trip times or lighter, radiation resistant power systems.

\section{GTO to GEO Mission}

Since LEO to GEO transfers using electric propulsion require long transit times in order to significantly enhance the net mass fraction, a geostationary transfer orbit (GTO) to geostationary orbit transfer may allow shorter thrust times, reduced shading and radiation exposure, and still provide a significant net mass fraction increase. Figures 4,5 , and 6 assume the same three propulsion technologies as used for the LEO to GEO transfer.

As with the LEO to GEO transfer the $\mathrm{N} 2 \mathrm{H} 4$ arcjets give no advantage. In addition, the nuclear reactor thrust times are again twice that of the photovoltaic technology. The actual trip times for photovoltaic technology are mainly increased by power degradation and shading effects. Results from SECKSPOT demonstrate that with unshielded GaAs arrays and thrust times $1 / 2$ to 2/3 of year, shading and power degradation causes trip times to increase only by a factor of about 1.1 over the thrust times without degradation .

To increase the net mass fraction by 0.1 , Hall thrusters or the $D$ 30 thrusters could be used with thrust times of 80 to 140 days for the former and 100 to 160 days for the latter. While this net mass increase seems minimal it can be made with power densities of only 5 to $3 \mathrm{~kW}$ per metric ton for Hall thrusters and 7.5 to $5 \mathrm{~kW}$ per metric ton for D-30 thrusters. Significant portions of these power densities are beginning to show up on geostationary satellites to power the payload, thus some (or perhaps all ) the power for the electric propulsion would already exist on the satellite. Since this power is also used for the satellite it can be considered payload and thus increases the net mass fraction. Figure 7 shows the net mass fraction curves considering all of the power system (the best case) as part of the net mass. With all the power system as payload the Hall thrusters increase the net mass fraction by 0.2 for a 100 day thrust time and a power density of $5 \mathrm{kw} /$ metric ton. The D-30 thruster technology improves the net mass fraction by 0.2 to 0.25 for a 75 to 110 day thrust time and power densities of 10 to $7 \mathrm{kw} /$ metric ton, respectively.

As with the LEO to GEO transfer the monetary cost of trip times and propulsion/power systems would have to be considered to truly prove the benefit of EP for GTO to GEO transfers. While spacecraft shielding is necessary the radiation dosage encountered is substantially less than LEO to GEO missions. Since the added time due to radiation and shading is small, radiation resistant arrays may not provide a significant benefit. 
For GTO to GEO missions in general, the delivered net mass fraction over chemical systems can be increased by a factor of 0.1 to 0.2 by utilizing thrusting times of 100 to 200 days and existing Hall and D-30 thruster technology. Improving the radiation resistance of photovoltaic power sources is not necessary. More net mass improvement would come with lighter power systems.

\section{Orbit Maintenance}

$\Delta V$ 's for orbit maintenance are usually orders of magnitude smaller than those for orbit transfer as shown by the example for geostationary orbit north south station keeping (NSSK) in table 3. However, at $\sim 50 \mathrm{~m} / \mathrm{s}$ per year a satellite with a ten or fifteen year lifetime requires 500 to $750 \mathrm{~m} / \mathrm{s}$ which implies a substantial amount of fuel if performed conventionally. To determine the approximate net mass advantage of EP for NSSK several simplifying assumptions are made. (1) Assume the 50 $\mathrm{m} / \mathrm{s}$ is equally divided over each day of the year (neglect eclipse periods) for short burn times (tens of minutes) at the orbit node. This assures thruster burns are as short as possible and centered about the orbit node to reduce the cosine losses caused by thrusting away from the node. (2) Require that the current satellite power level and system (especially batteries) can supply the electric thruster system and the payload simultaneously. (3) Assume two operating thrusters with cant angles of $17^{\circ}, 30^{\circ}$ and $45^{\circ}$ for $\mathrm{N} 2 \mathrm{H} 4$ arcjets, Xenon D-30 thrusters, and Xenon Hall thrusters, respectively. These cant angles are imposed to eliminate plume impingement on the solar array. The equivalent one thruster power, efficiencies, and Isp's for each thruster type and cant angle are shown in Table 4.

Setting the power density at $1 \mathrm{kw} / 1000 \mathrm{~kg}$ and noting that the power system is part of the net mass, Figure 8 is generated. From Figure 8 notable net mass fraction increases can be gained for 10 and 15 year service times. The D-30 ion system preserves a net mass fraction above .95 even for the 15 year service time. Converting the thrusting times per day shown in figure 8 to hours of operation shows that the Hall and Ion thrusters have sufficient lifetimes but that extra arcjets may be required. (These thrust times per day will be increased somewhat if thrusting is not allowed during eclipse periods.) Since the power system is already on board to power the payload and a $1 \mathrm{~kW} / \mathrm{kg}$ is reasonable for current satellites, no new power technology seems needed except, perhaps for batteries that can handle more cycles demanded by the daily use by the thrusters. In fact, Telstar IV launched in 1994 has N2H4 arcjets for NSSK.

\section{Conclusions}

It has been shown that electric propulsion depends on many aspects of power technology (e.g. mass, radiation resistance, cycling, and cost) to provide substantial net mass benefits over chemical propulsion. With proper radiation resistance photovoltaic systems are shown to require less thrusting time than nuclear reactor systems. This, combined with the greater maturity of photovoltaic systems make them more desirable (at least in the near term ) than nuclear systems.
LEO to GEO missions require radiation resistant power systems that are also light (20 to $40 \mathrm{~kg} / \mathrm{kW}$ including PMAD) in order to more than double chemical net mass fractions and still keep trip times below a year. Currently, the best radiation resistant photovoltaic power system technology is the concentrator array. GTO to GEO missions using EP can provide a net mass fraction increase of 0.1 to 0.2 with trip times 100 to 250 days with power systems that are light, but not radiation resistant. With on-board payload power densities in the 4 to $7 \mathrm{~kW} /$ metric ton range EP can provide net mass fraction gains approaching 0.3 for GTO to GEO missions with half year trip times. Orbit maintenance for geosynchronous satellites (NSSK) can be accomplished with current power technologies and power densities ( $\sim 1 \mathrm{~kW} /$ metric ton) to provide a net mass fraction benefit in the 0.1 to 0.2 range depending on service time and thruster technology.

Of the three thruster systems only the Xenon Hall and Xenon D30 Ion Thrusters showed net mass benefits over chemical systems for LEO to GEO and GTO to GEO missions. The $\mathrm{N} 2 \mathrm{H} 4$ arcjet performance is equivalent to chemical systems for these transfers. All three thruster systems gave net mass increases for geosynchronous NSSK orbit maintenance.

\section{Acknowledements}

Research for this paper was done at NASA Lewis Research Center's Advanced Space Analysis Office (Contract NAS327186).

\section{References}

1.Oleson, S.R. An Analytical Optimization of Electric Propulsion Orbit Transfer Vehicles, CR-191129, NASA Lewis Research Center, May 1993.

2. Stuhlinger, E. Ion Propulsion for Space Flight. McGrawHill: New York, 1964

3.Gilland, J.H. Mission and System Optimization of Nuclear Electric Propulsion Vehicles for Lunar and Mars Missions, CR189058, NASA Lewis Research Center, December 1991.

4.Rawlin, V.K., Majcher, G.A Mass Comparisons of Electric Propulsion Systems for NSSK of Geosynchronous $S$ pacecraft,AIAA-91-2347, 27th Joint Propulsion Conference, Sacramento, CA, June 24-27, 1991.

5.Myers, R.M., Oleson, S.R. Small Satellite Electric Propulsion Options, 29th Intersociety Energy Conversion Engineering Conference, Monterey, CA, August 7-12, 1994. 6. Jahn, R.G. Physics of Electric Propulsion. McGraw-Hill: New York, 1968

7. Larson, W.J. et al. Space Mission Analysis and Design Microcosm Inc, Torrence CA.

8. Agrawal, B.N. Design of Geosynchronous Spacecraft ,Prentice-Hall, Inc. Englewood Cliffs, NJ.

9. Manner, D.B., TROPIX Power System Architecture, unpublished study, NASA Lewis Research Center, 1991. 10.Edelbaum, T.N. "Propulsion Requirements for Controllable Satellites", ARS Joumal, 31: 1079-1089. August 1961.

11. Free, B.A. North-South Stationkeeping with Electric Propulsion Using Onboard Battery Power, COMSAT Laboratories, 1980

12. Pollard, J.E. et al., Electric Propulsion Flight Experience and Technology Readiness, AIAA , 1993 


\begin{tabular}{|c|c|c|c|c|c|c|}
\hline \multicolumn{7}{|c|}{ Table 1. Thruster System Parameters } \\
\hline Name & Isp & Efficiency & $\begin{array}{c}\text { Input } \\
\text { Power* }\end{array}$ & $\begin{array}{c}\text { Specific } \\
\text { Mass ** }\end{array}$ & Lifetime & Ref. \\
\hline $\begin{array}{c}\text { Xenon Ion Derated 30 } \\
\text { cm }\end{array}$ & $2285 \mathrm{~s}-3300 \mathrm{~s}$ & $0.46-0.61$ & $640-2560 \mathrm{~W}$ & $44-15 \mathrm{~kg} / \mathrm{kW}$ & $8000 \mathrm{hrs} @ 2.5 \mathrm{~kW}$ & Rawlin(4) \\
\hline Xenon Hall Thruster & $1500 \mathrm{~s}-1550 \mathrm{~s}$ & $0.47-0.48$ & $700-1500 \mathrm{~W}$ & $21-14 \mathrm{~kg} / \mathrm{kW}$ & $4000 \mathrm{hrs} \mathrm{@} 1.5 \mathrm{~kW}$ & $\mathrm{Myers}(5)$ \\
\hline N2H4 Arcjet & $357 \mathrm{~s}-600 \mathrm{~s}$ & $0.34-0.28$ & $690-2220 \mathrm{~W}$ & $20-8 \mathrm{~kg} / \mathrm{kW}$ & $1000 \mathrm{hrs} @ 2.2 \mathrm{~kW}$ & Rawlin(4) \\
\hline * Into PPU & **Includes Thruster, control unit, cabling, gimbal, support structure and PPU & \\
\hline
\end{tabular}

\begin{tabular}{|c|c|c|c|c|}
\hline \multicolumn{7}{|c|}{ Table 2. Power Subsystem Parameters } \\
\hline Component & Type & Power Range & Specific Mass & Reference \\
\hline Power Source & Photovoltaic & $0.2-25 \mathrm{~kW}$ & $38.5-10 \mathrm{~kg} / \mathrm{kW}$ & McDermott(7) \\
\hline Power Source & Solar Thermal & $1-300 \mathrm{~kW}$ & $111-67 \mathrm{~kg} / \mathrm{kW}$ & McDermott(7) \\
\hline Power Source & Radioisotope & $0.2-10 \mathrm{~kW}$ & $125-100 \mathrm{~kg} / \mathrm{kW}$ & McDermott(7) \\
\hline Power Source & Nuclear Reactor & $25-100 \mathrm{~kW}$ & $67-45 \mathrm{~kg} / \mathrm{kW}$ & McDermott(7) \\
\hline Power Regulator & Shunt & $1.25-5 \mathrm{~kW}$ & $7.5 \mathrm{~kg} / \mathrm{kW}$ & Agrawal $(8)$ \\
\hline Power Regulator & Regulator \& Converter & $2.2 \mathrm{~kW}$ & $5.4 \mathrm{~kg} / \mathrm{kW}$ & $\operatorname{Manner}(9)$ \\
\hline Power Distribution & Distributor \& Harness & $2.2 \mathrm{~kW}$ & $4 \mathrm{~kg} / \mathrm{kW}$ & $\operatorname{Manner}(9)$ \\
\hline
\end{tabular}

\begin{tabular}{|c|c|c|c|c|}
\hline \multicolumn{5}{|c|}{ Table 3. Sample Missions } \\
\hline Mission & $\begin{array}{c}\text { Initial Orbit } \\
\text { Altitude;Incl. }\end{array}$ & $\begin{array}{c}\text { Final Orbit } \\
\text { Altitude;Incl }\end{array}$ & $\begin{array}{c}\text { Mission } \\
\Delta \mathbf{V}\end{array}$ & $\Delta \mathbf{V}$ Source \\
\hline $\begin{array}{c}\text { Low Earth Orbit to } \\
\text { Geosynchronous }\end{array}$ & $400 \mathrm{~km}$ circular; $28.5^{\circ}$ & $\begin{array}{c}-35786 \mathrm{~km} \\
\text { circular; } 0^{\circ}\end{array}$ & $5.9 \mathrm{~km} / \mathrm{s}$ & Edelbaum(10) \\
\hline $\begin{array}{c}\text { Geosynchronous Transfer to } \\
\text { Geosynchronous }\end{array}$ & $167 \times 35786 \mathrm{~km} ; 28.5^{\circ}$ & $\begin{array}{c}35786 \mathrm{~km} \\
\text { circular; } 0^{\circ}\end{array}$ & $2.7 \mathrm{~km} / \mathrm{s}$ & $\begin{array}{c}\text { SECKSPOT } \\
\text { Run }\end{array}$ \\
\hline $\begin{array}{c}\text { Geosynchronous North/South } \\
\text { Stationkeeping }\end{array}$ & $\begin{array}{c}\text { Maintain satellite within } \\
0.1^{\circ} \text { of a } 0^{\circ} \text { incl. }\end{array}$ & - & $\begin{array}{c}\sim 50 \mathrm{~m} / \mathrm{s} \\
\text { /year }\end{array}$ & Agrawal(8) \\
\hline
\end{tabular}

\begin{tabular}{|c|c|c|c|c|c|c|c|}
\hline \multicolumn{7}{|c|}{ Table 4. Equivalent One Thruster Parameters } & \\
\hline \#hrusters & Thruster & $\begin{array}{c}\text { PPU Input } \\
\text { Power } \\
\text { (each) }\end{array}$ & Isp & $\begin{array}{c}\text { Overall } \\
\text { Efficiency }\end{array}$ & $\begin{array}{c}\text { Cant } \\
\text { Angle }\end{array}$ & $\begin{array}{c}\text { One Thivalent } \\
\text { Power }\end{array}$ & $\begin{array}{c}\text { Equivalent } \\
\text { Isp }\end{array}$ \\
\hline 2 & N2H4 Arcjet & $2.20 \mathrm{~kW}$ & $600 \mathrm{~s}$ & 0.28 & $17^{\circ}$ & $4.02 \mathrm{~kW}$ & $574 \mathrm{~s}$ \\
\hline 2 & Xe Ion D-30 & $2.56 \mathrm{~kW}$ & $3300 \mathrm{~s}$ & 0.61 & $30^{\circ}$ & $3.84 \mathrm{~kW}$ & $2858 \mathrm{~s}$ \\
\hline 2 & Xe Hall & $1.50 \mathrm{~kW}$ & $1550 \mathrm{~s}$ & 0.48 & $45^{\circ}$ & $1.50 \mathrm{~kW}$ & $1096 \mathrm{~s}$ \\
\hline
\end{tabular}

Figure 1. LEO to GEO Performance with Photovoltaic Technology

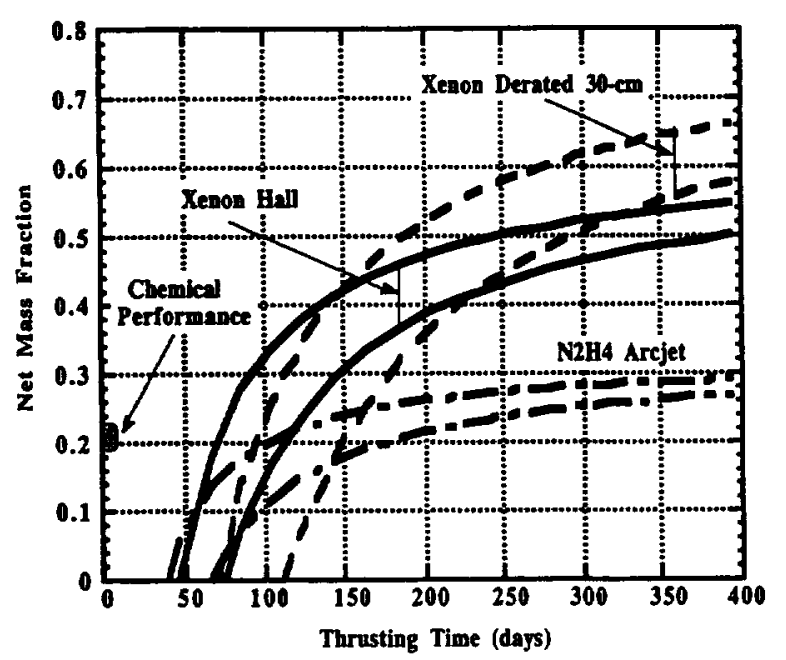

Figure 2. LEO to GEO Performance with Nuclear Reactor Technology

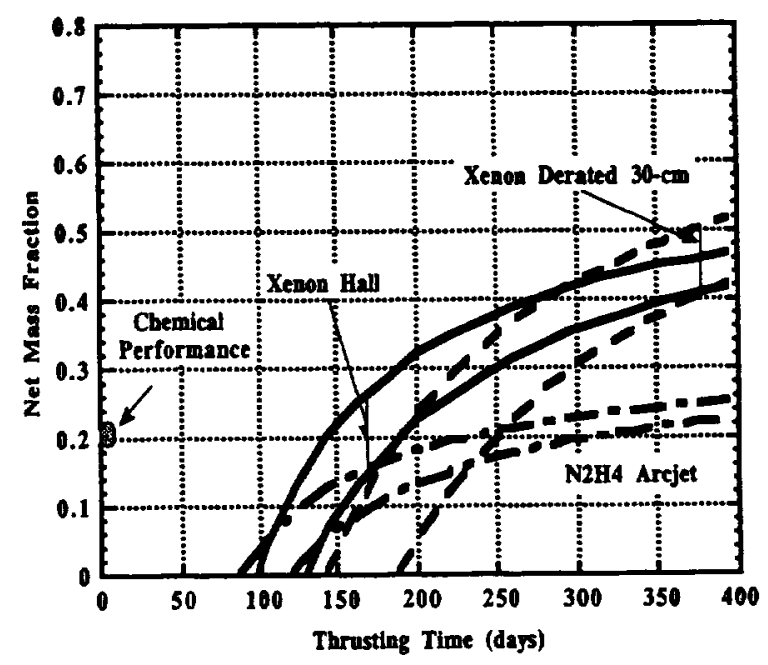


Figure 3. Required Power Densities for LEO to GEO Missions
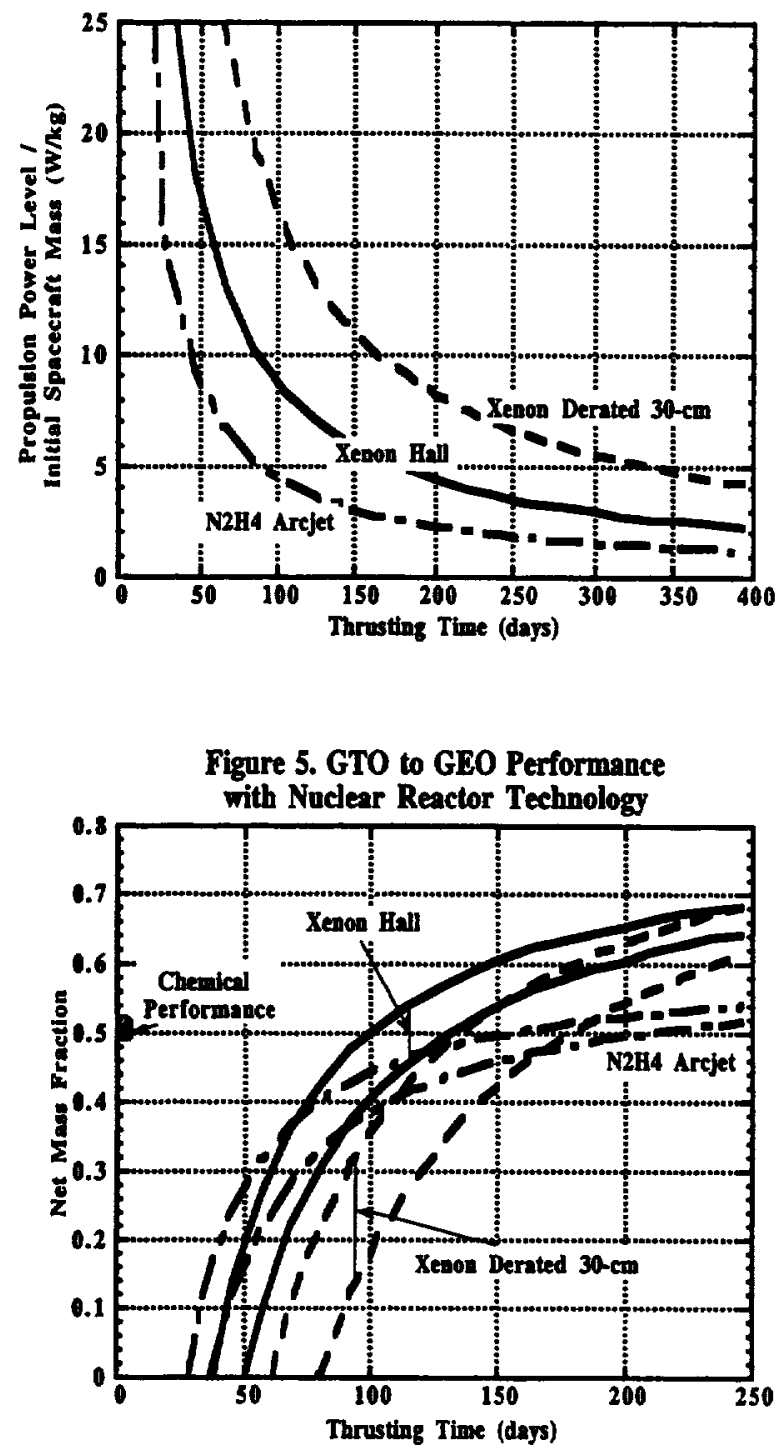

Figure 7. GTO to GEO Performance Assuming 'Tree' Photovoltaic Power

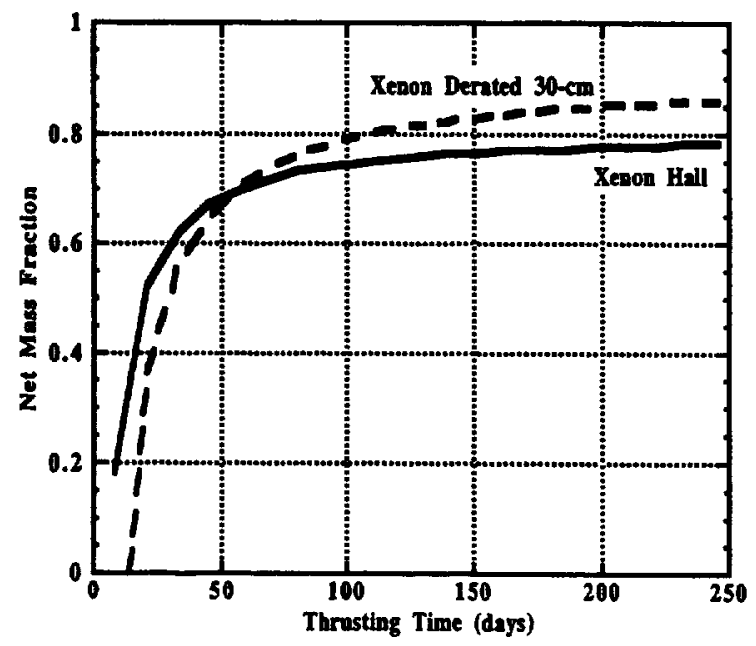

Figure 4. GTO to GEO Performance with Photovoltric Technology

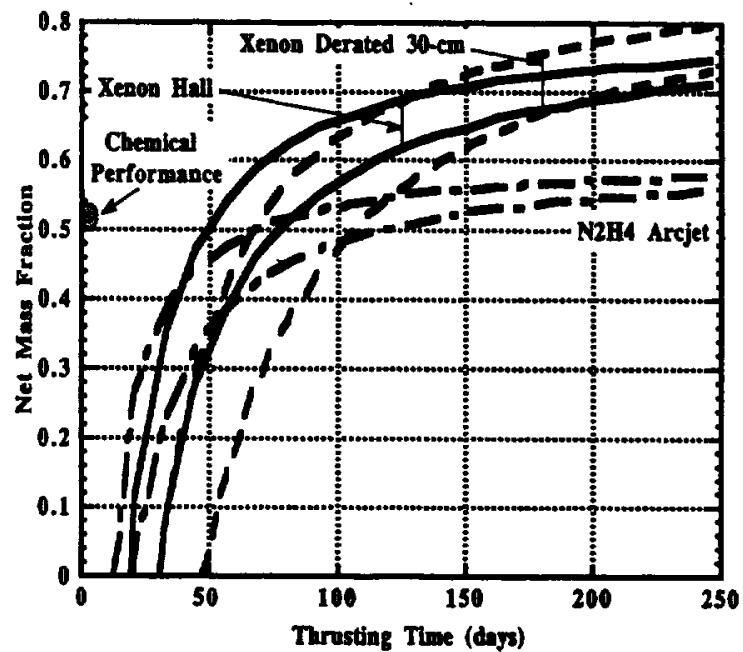

Figure 6. Required Power Densities for GTO to GEO Missions

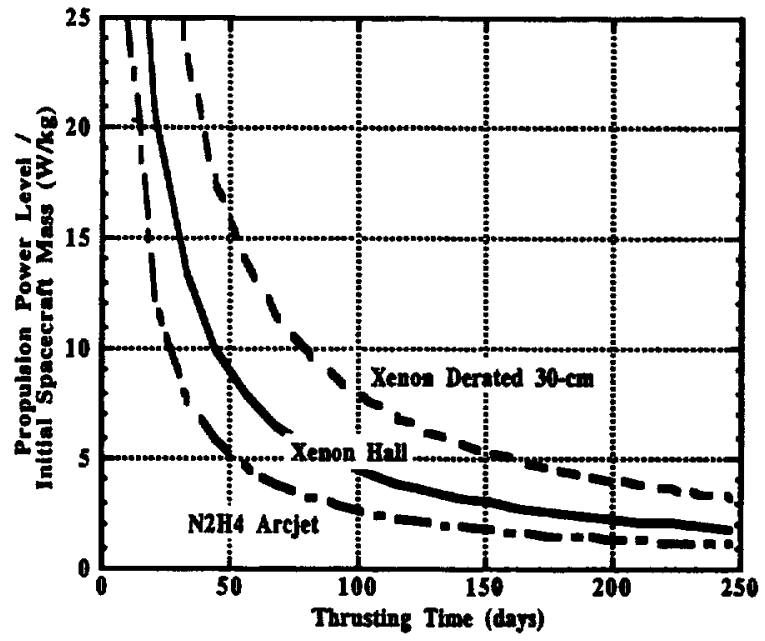

Figure 8. GEO NSSK Performance with Photoroltaic Technology

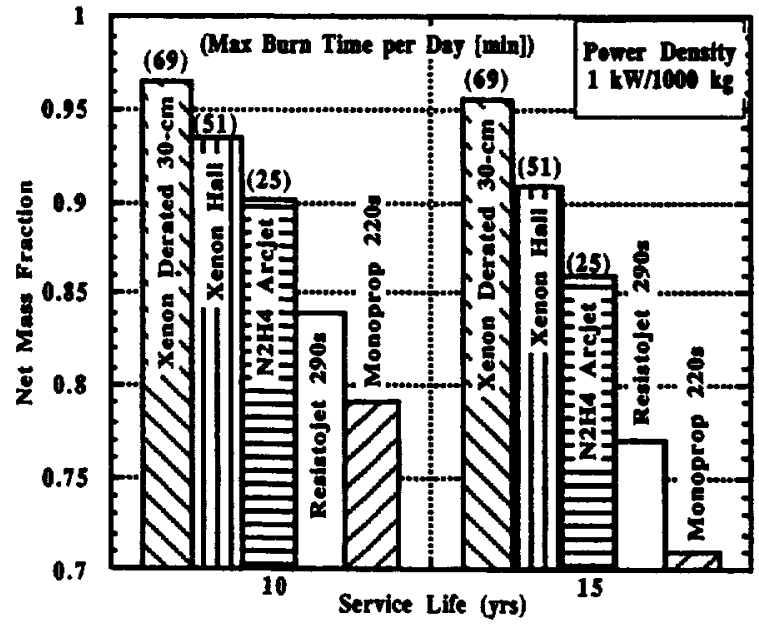





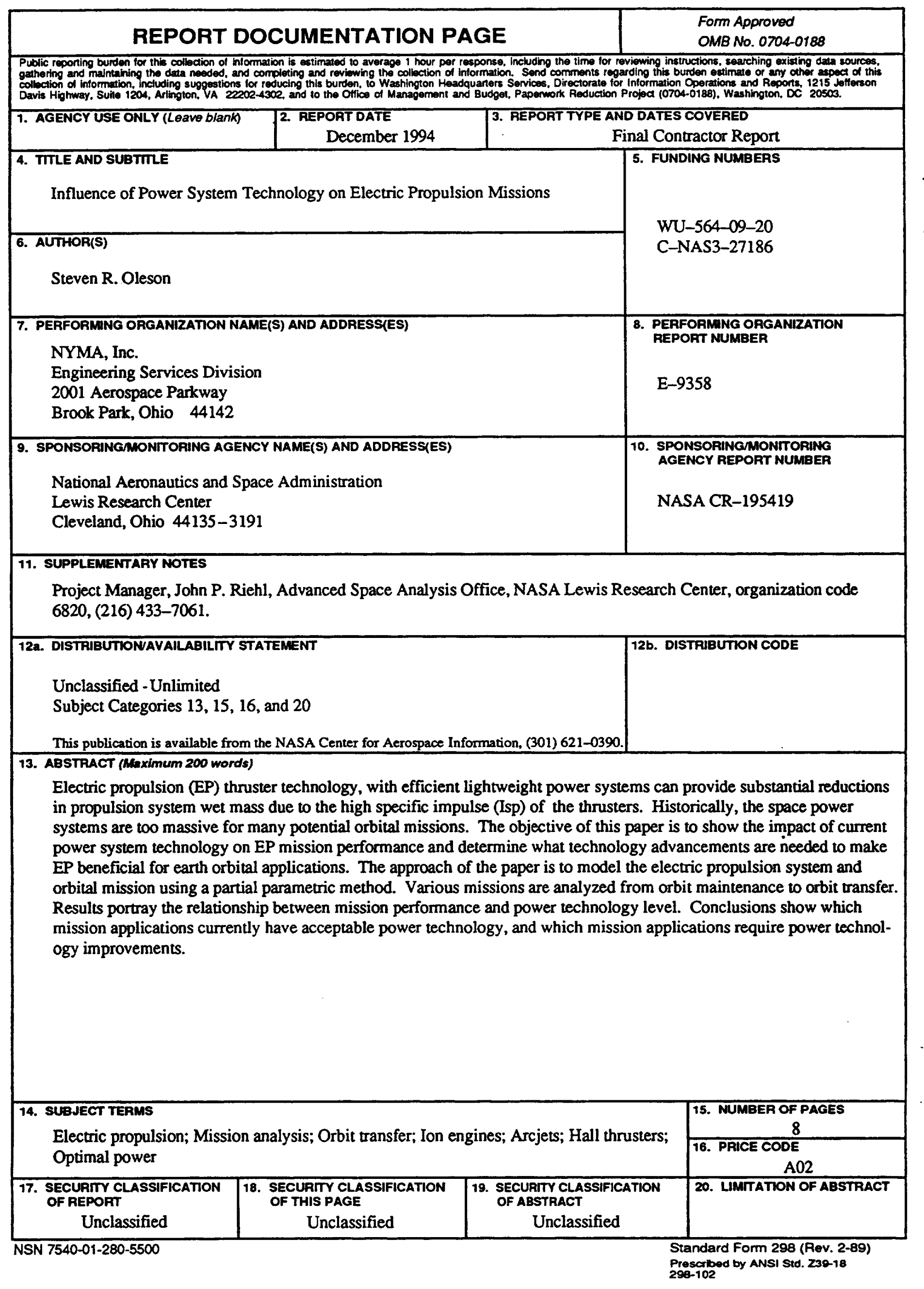

